Louisiana State University

LSU Digital Commons

7-10-2007

\title{
Structure and mechanism of the genomically encoded fosfomycin resistance protein, FosX, from Listeria monocytogenes
}

\author{
Kerry L. Fillgrove \\ Vanderbilt University School of Medicine \\ Svetlana Pakhomova \\ Louisiana State University \\ Matthew R. Schaab \\ Vanderbilt University School of Medicine \\ Marcia E. Newcomer \\ Louisiana State University \\ Richard N. Armstrong \\ Vanderbilt University School of Medicine
}

Follow this and additional works at: https://digitalcommons.Isu.edu/biosci_pubs

\section{Recommended Citation}

Fillgrove, K., Pakhomova, S., Schaab, M., Newcomer, M., \& Armstrong, R. (2007). Structure and mechanism of the genomically encoded fosfomycin resistance protein, FosX, from Listeria monocytogenes.

Biochemistry, 46 (27), 8110-8120. https://doi.org/10.1021/bi700625p

This Article is brought to you for free and open access by the Department of Biological Sciences at LSU Digital Commons. It has been accepted for inclusion in Faculty Publications by an authorized administrator of LSU Digital Commons. For more information, please contact ir@lsu.edu. 


\title{
Structure and Mechanism of the Genomically Encoded Fosfomycin Resistance Protein, FosX, from Listeria monocytogenes ${ }^{\dagger,}$
}

\author{
Kerry L. Fillgrove, ${ }^{\S, l}$ Svetlana Pakhomova, ${ }^{\perp}$ Matthew R. Schaab, ${ }^{\S}$ Marcia E. Newcomer, ${ }^{\perp}$ and \\ Richard N. Armstrong*,\$ \\ Departments of Biochemistry and Chemistry, Center in Molecular Toxicology and Vanderbilt Institute of Chemical Biology, \\ Vanderbilt University, Nashville, Tennessee 37232-0146, and Departments of Biological Sciences and Chemistry, \\ Louisiana State University, Baton Rouge, Louisiana 70803
}

Received April 2, 2007; Revised Manuscript Received April 26, 2007

\begin{abstract}
The fosfomycin resistance protein, FosX, catalyzes the hydration of the antibiotic fosfomycin, $(1 R, 2 S)$-epoxypropylphosphonic acid. Genes encoding the enzyme are found in several pathogenic microorganisms. The structure and mechanism of action of the genomically encoded FosX enzyme from Listeria monocytogenes (Fos $\mathrm{X}^{\mathrm{LMATCC}}$ ) obtained from the American Type Culture Collection are reported. The gene harbors 31 point mutations, and as a consequence, the protein differs in 10 amino acid residues from the previously reported FosX encoded in the genome of the EGD strain of L. monocytogenes (Fos $\mathrm{X}^{\mathrm{LMEGD}}$ ). The Fos $\mathrm{X}^{\mathrm{LMATCC}}$ enzyme is shown to catalyze the addition of water to the $\mathrm{C} 1$ position of the antibiotic with inversion of configuration at $\mathrm{C} 1$. The reaction involves $\mathrm{Mn}$ (II) activation of the oxirane oxygen and E44 acting as a general base. The structure of the enzyme has been determined from six different crystal forms of the protein. The structures of the enzyme without metal bound are similar but differ in the loop regions. Perhaps the most informative structure is the one with the product bound. This structure shows that the phosphonate group of the product is bound in an orientation that is different than that of fosfomycin bound to the related enzyme, FosA. The implication is that the substrate may also be bound in a different orientation in FosX. A high-resolution structure (1.44 A resolution) of the enzyme reveals a unique conformation in which the C-terminal tail of the protein coordinates to the $\mathrm{Mn}$ (II) center via the carboxylate of E126. The kinetic characterization of the E126Q mutant indicates that this conformation of the protein is probably not relevant to the function of the enzyme. Kinetic analysis of mutants of active site residue E44 is consistent with its proposed roll as a general base catalyst in the addition of water to the antibiotic.
\end{abstract}

Antibiotic resistance in pathogenic microorganisms is an ever-increasing problem worldwide where bacterial resistance to many of the "last resort" antibiotics has been observed in recent years (1). Antimicrobial resistance is often the result of the selective pressure on microbial populations resulting from the use or overuse of antibiotics. Three of the most common bacterial defenses against antibiotics include the alteration of the antibiotic transport or uptake mechanism, mutation of the antibiotic target, or inactivation or sequestration of the antibiotic by resistance proteins (1). All three of these defense mechanisms have been observed with respect to the natural product fosfomycin $\mathbf{1}$ (Scheme 1).

Supported by Grants R01 AI042756, P30 ES000267, and T32 ES007028 from the National Institutes of Health and the Louisiana Governor's Biotechnology Initiative.

$\ddagger$ The coordinates for the structures reported in this work have been deposited in the Protein Data Bank under file names $2 \mathrm{P} 7 \mathrm{~K}, 2 \mathrm{P} 7 \mathrm{~L}$, 2P7M, 2P7O, 2P7P, 2P7Q.

* To whom correspondence should be addressed. E-mail: r.armstrong@vanderbilt.edu. Fax: (615) 343-2921. Telephone: (615) 343-2920.

$\S$ Vanderbilt University.

"Current address: Merck Research Laboratories, West Point, PA 19486.

${ }^{\perp}$ Louisiana State University.
Scheme 1
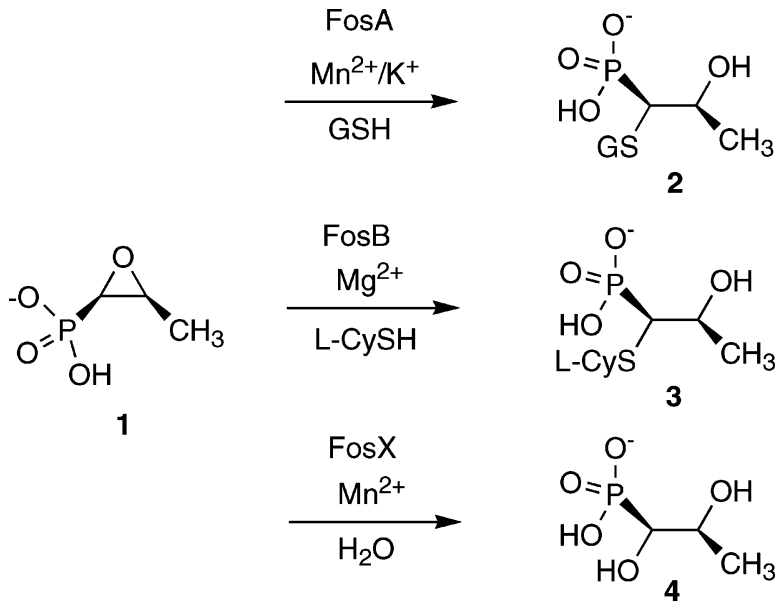

The antimicrobial properties of fosfomycin were first reported by Merck in 1969 where the molecule was shown to be effective against both Gram-positive and Gram-negative bacteria (2-4). Fosfomycin inhibits the enzyme UDP- $N$ acetylglucosamine-3-enolpyruvyltransferase (MurA), ${ }^{1}$ which catalyzes the first committed step in bacterial cell wall biosynthesis. Later studies determined that fosfomycin ir- 
Scheme 2

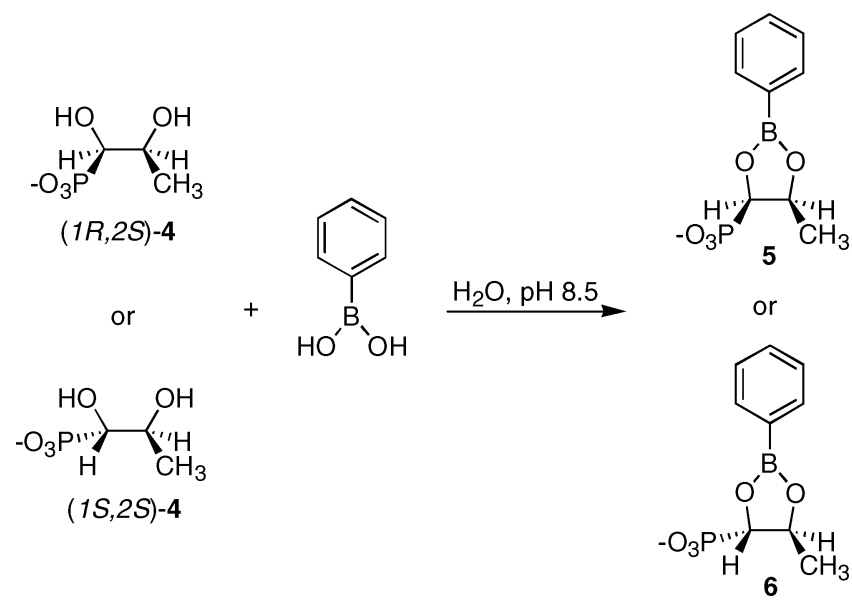

reversibly inactivates MurA by alkylating an active site cysteine residue (5-7). Upon introduction into the clinic, resistance to fosfomycin emerged rapidly and was attributed to mutations affecting antibiotic transport $(8,9)$ and to mutations in the MurA target itself (10).

Several years later, a new mechanism of fosfomycin resistance was identified and linked to a plasmid obtained from clinical isolates (11). This plasmid contained a gene encoding a resistance protein (FosA), which catalyzes the addition of glutathione to the antibiotic (Scheme 1), rendering it inactive $(12,13)$. Extensive characterization of this enzyme demonstrated that it is a $\mathrm{Mn}(\mathrm{II})$-dependent glutathione transferase (14) that exhibits an enhanced activity in the presence of monovalent cations (15). A FosA homologue from Bacillus subtilus (FosB) also acts as a thioltransferase enzyme catalyzing the $\mathrm{Mg}^{2+}$-dependent addition of L-cysteine to the epoxide ring of fosfomycin (Scheme 1) (16). Mining the microbial genome database with the sequences of FosA and FosB identified a new class of fosfomycin resistance proteins called FosX (17).

The FosX enzymes catalyze the hydration of fosfomycin (Scheme 1) in generating the vicinal diol 4. Genes encoding FosX homologues have been identified in Mesorhizobium loti, Desulfitobacterium hafniense, and pathogens Listeria monocytogenes, Brucella melitensis, and Clostridium botulinum. Studies of the FosX enzymes from M. loti (Fos $\mathrm{X}^{\mathrm{ML}}$ ) and L. monocytogenes (Fos $\mathrm{X}^{\mathrm{LM}}$ ) demonstrated that the addition of a solvent-derived oxygen occurs in a regiospecific manner at $\mathrm{C} 1$ of fosfomycin (17), but the stereochemical course of the reaction has remained undefined. The crystal structure of the Fos $\mathrm{X}^{\mathrm{ML}}$ enzyme (17) provided some insight into the catalytic mechanism but also left many unanswered questions regarding its modest catalytic activity when compared to that of Fos $\mathrm{X}^{\mathrm{LM}}$ from L. monocytogenes. Determination of the structure of the Fos $\mathrm{X}^{\mathrm{LM}}$ could elucidate the molecular bases for these differences.

In this paper, we present the assignment of the absolute configuration of the $\mathrm{C} 1$ center of the Fos $\mathrm{X}$ product and the identification and characterization of a naturally occurring

\footnotetext{
${ }^{1}$ Abbreviations: MurA, UDP- $N$-acetylglucosamine-3-enolpyruvyltransferase; HEPES, 4-(3-hydroxyethyl)piperazine-1-ethanesulfonic acid; Tris, tris(hydroxymethyl)aminomethane; EDTA, ethylenediaminetetraacetic acid; DTT, dithiothreitol; DEAE, diethylaminoethyl; TMS, trimethylsilyl; PEG, polyethylene glycol; MIC, minimum inhibitory concentration; VOC, vicinal oxygen chelate.
}

genomically encoded L. monocytogenes FosX mutant (Fos$\left.\mathrm{X}^{\mathrm{LMATCC}}\right)$. Extensive structural characterization of this mutant resulted in identification of a unique conformation of the C-terminal tail and provides evidence that fosfomycin may bind to Fos X enzymes in an orientation different from that observed in the FosA proteins (18). Several site-specific mutants are characterized kinetically so the roles of key residues in the catalytic mechanism could be probed.

\section{EXPERIMENTAL PROCEDURES}

Materials. Fosfomycin disodium salt was purchased from Fluka. The pET20b(+) plasmid and Rosetta(DE3) cells were from Novagen (Madison, WI). Phenylboronic acid, HEPES (free acid), and $\mathrm{D}_{2} \mathrm{O}$ (99.99 at. \% D) were from Aldrich. $\mathrm{N}, \mathrm{O}$-Bis(trimethylsilyl)acetamide (BSA) and trimethylchlorosilane were from Pierce (Rockford, IL). Puratronic grade $\mathrm{MnCl}_{2}$ was obtained from Alfa Aesar (Ward Hill, MA). The oligonucleotide primers used for cloning and mutagenesis were obtained from Invitrogen (Carlsbad, CA). All other chemicals were reagent grade or better and obtained from commercial sources.

Cloning, Expression, and Purification of the Fosfomycin Resistance Protein from L. monocytogenes. L. monocytogenes genomic DNA (19115D) was obtained from American Type Culture Collection (Manassas, VA). The $1 m o 1702$ gene was amplified from genomic DNA, via PCR, using synthetic oligonucleotide primers: forward, 5'-AT AGT ATA CAT ATG ATT TCA GGA TTA AGC CAT ATC AC-3'; and reverse, 5'-AAA TTT GGA TCC CTA TTC GTG ATA CCT TTT CAG C-3'. The primers were designed to incorporate $5^{\prime} \mathrm{NdeI}$ and 3' BamHI restriction sites. After amplification, the PCR product was purified using the QiaQuick PCR purification kit (Qiagen Inc., Valencia, CA). The PCR product and pET20b(+) DNA were doubly digested with the indicated restriction enzymes, and the digestion products were gel purified and subsequently ligated to form the Imo1702ATCC:pET20b(+) expression plasmid. Imo1702 was overexpressed in Escherichia coli Rosetta(DE3) cells in the following manner. Typically, cells from an overnight culture, grown in LB medium containing ampicillin $(70 \mu \mathrm{g} /$ $\mathrm{mL})$ and chloramphenicol $(14 \mu \mathrm{g} / \mathrm{mL})$, were used to inoculate individual $1.5 \mathrm{~L}$ cultures of the same medium. The cells were grown at $30{ }^{\circ} \mathrm{C}$ and $225 \mathrm{rpm}$. When an $\mathrm{OD}_{600}$ of $0.5-0.7$ was reached, the cells were induced by the addition of lactose (final concentration of $6 \mathrm{mM}$ ). The culture was incubated for an additional $6 \mathrm{~h}$ at $30^{\circ} \mathrm{C}$, and the cells were harvested by centrifugation and stored frozen at $-80^{\circ} \mathrm{C}$.

The cell pellet from $3 \mathrm{~L}$ of liquid culture was thawed on ice and resuspended in $25 \mathrm{~mL}$ of buffer A $25 \mathrm{mM}$ Tris and $75 \mathrm{mM} \mathrm{NaCl}$ (pH 7.5)] containing $0.1 \mathrm{mg} / \mathrm{mL}$ lysozyme. The cell suspension was incubated at $25{ }^{\circ} \mathrm{C}$ for $15 \mathrm{~min}$ followed by incubation on ice for $15 \mathrm{~min}$. An additional 60 $\mathrm{mL}$ of buffer $\mathrm{A}$ was added to the cell suspension, and the cells were lysed by sonication on ice. The lysate was then centrifuged ( $25000 \mathrm{~g}$ for $30 \mathrm{~min}$ ) to remove the cell debris. The supernatant was treated with streptomycin sulfate $(1 \%$, $\mathrm{w} / \mathrm{v}$ ) and centrifuged $(30000 \mathrm{~g}$ for $30 \mathrm{~min})$. The resulting supernatant was dialyzed against $2 \mathrm{~L}$ of buffer A containing $250 \mathrm{mM}$ EDTA and $1 \mathrm{mM}$ DTT. The dialysate was applied to a $2.5 \mathrm{~cm} \times 12 \mathrm{~cm}$ DEAE-cellulose column (Whatman, Maidstone, U.K.), and the column was developed with a 
linear 75 to $400 \mathrm{mM} \mathrm{NaCl}$ gradient. Fractions containing Fos $\mathrm{X}^{\text {LMATCC }}$ were pooled and dialyzed against $30 \mathrm{mM} \mathrm{KH}_{2}$ $\mathrm{PO}_{4}$ (pH 7.0) containing $1 \mathrm{mM}$ DTT. The dialysate was then loaded onto a $1.5 \mathrm{~cm} \times 8 \mathrm{~cm}$ hydroxyapatite column, and Fos $\mathrm{X}^{\mathrm{LMATCC}}$ was found in the flow-through fractions. The protein was dialyzed against buffer B $[25 \mathrm{mM}$ HEPES $(\mathrm{pH}$ 7.5)] containing $100 \mathrm{mM} \mathrm{NaCl}, 5 \mathrm{mM}$ EDTA, $1 \mathrm{mM}$ DTT, and $3 \mathrm{~g}$ of Chelex 100 to generate a metal-free protein solution. The dialysate was concentrated to $10 \mathrm{mg} / \mathrm{mL}$ and applied to a $1.6 \mathrm{~cm} \times 60 \mathrm{~cm}$ Sephacryl S-100 column that had been equilibrated in buffer B containing $100 \mathrm{mM} \mathrm{NaCl}$ and $0.5 \mathrm{mM}$ EDTA. Extensive dialysis against buffer $\mathrm{B}$ containing $1 \mathrm{mM}$ DTT and Chelex 100 resin yielded pure metal-free protein. The protein was concentrated and stored frozen at $-80{ }^{\circ} \mathrm{C}$.

Generation of the Diol Product 4. Fosfomycin (1.5 g) was dissolved in $15 \mathrm{~mL}$ of $\mathrm{H}_{2} \mathrm{O}$, and the $\mathrm{pH}$ was adjusted to 7.5 via addition of $\mathrm{HCl}$. $\mathrm{MnCl}_{2}$ was added to the fosfomycin solution to a final concentration of $50 \mu \mathrm{M}$. The reaction was then initiated by the addition of Fos $\mathrm{X}^{\mathrm{LMATCC}}$ (final concentration of $10 \mu \mathrm{M}$ ) and allowed to proceed at room temperature. The conversion of fosfomycin to the diol product was monitored by quenching a $500 \mu \mathrm{L}$ aliquot of the reaction mixture by vortexing after the addition of $40 \mu \mathrm{L}$ of $\mathrm{CHCl}_{3}$. The aqueous layer after centrifugation was then demetalated by incubation with $50 \mathrm{mg}$ of Chelex 100 for several hours. The Chelex 100 resin was removed by centrifugation, and $400 \mu \mathrm{L}$ of the solution was combined with $100 \mu \mathrm{L}$ of $\mathrm{D}_{2} \mathrm{O}$ (99.9 at. \% D) and a ${ }^{1} \mathrm{H}$-decoupled ${ }^{31} \mathrm{P}$ NMR spectrum acquired. The reaction was considered complete when fosfomycin could no longer be detected by ${ }^{31} \mathrm{P}$ NMR. Fosfomycin: ${ }^{31} \mathrm{P}$ NMR (121.495 MHz, D $\left.2 \mathrm{O}\right) \delta 11.16$ (s). 1,2-Dihydroxypropylphosphonic acid: ${ }^{31} \mathrm{P}$ NMR (121.495 $\left.\mathrm{MHz}, \mathrm{D}_{2} \mathrm{O}\right) \delta 16.95$ (s).

When the enzyme-catalyzed reaction was complete, the enzyme was denatured by vortexing after the addition of 0.5 $\mathrm{mL}$ of $\mathrm{CHCl}_{3}$. The aqueous layer after centrifugation was incubated with $500 \mathrm{mg}$ of Chelex 100 resin for several hours to remove the $\mathrm{Mn}(\mathrm{II})$. The Chelex resin was removed by centrifugation, and the 1,2-dihydroxypropylphosphonic acid was taken to dryness by lyophilization.

Determination of the Absolute Configuration at $\mathrm{Cl}$ of the Reaction Product. The generation of the boronate ester of the FosX product was based upon the method of Islam et al. (19). A stock solution of phenylboronic acid was prepared by solubilizing the acid in $\mathrm{H}_{2} \mathrm{O}$ after titrating the solution to $\mathrm{pH} 8.5$ with $\mathrm{NaOH} ; 1.2$ molar equiv of phenylboronic acid was added to a $150 \mathrm{mM}$ solution of the diol product (4), and the final $\mathrm{pH}$ was adjusted to 8.5 by addition of $\mathrm{NaOH}$. The reaction was allowed to proceed at room temperature for $30 \mathrm{~min}$ and then the mixture taken to dryness by vacuum centrifugation. The dried sample was then dissolved in $\mathrm{D}_{2} \mathrm{O}$ (99.96 at. \% D), and the phenylboronate ester complex was characterized by ${ }^{1} \mathrm{H},{ }^{13} \mathrm{C},{ }^{31} \mathrm{P}$, and NOESY NMR spectroscopy: ${ }^{1} \mathrm{H}$ NMR (300.13 MHz, $\left.\mathrm{D}_{2} \mathrm{O}, \mathrm{pD} 8.9\right) \delta 1.15(\mathrm{~d}, 3 \mathrm{H}$, $J=6.3 \mathrm{~Hz}), 3.37(\mathrm{~s}, 1 \mathrm{H}), 4.03(\mathrm{~s}, 1 \mathrm{H}), 7.29(\mathrm{~m}, 3 \mathrm{H}), 7.6$ $(\mathrm{d}, 2 \mathrm{H}, J=7.4 \mathrm{~Hz}) ;{ }^{13} \mathrm{C}$ NMR $\left(75.471 \mathrm{MHz}, \mathrm{D}_{2} \mathrm{O}\right) \delta 18.76$ $(\mathrm{d}, J=8.4 \mathrm{~Hz}), 68.37$ (s), $73.40(\mathrm{~d}, J=140 \mathrm{~Hz}), 127.62$ (s), 127.90 (s), 132.29 (s); ${ }^{31} \mathrm{P}$ NMR (121.495 MHz, D $\left.2 \mathrm{O}\right) \delta$ 16.95 (s).

Steady State Kinetics of FosX. The kinetic assays were conducted either by gas chromatography and mass spec- trometry (GC-MS) on a ThermoFinnigan DSQ GC-MS system with $n$-butylphosphonate as an internal standard as previously described (20) or by gas chromatography with flame ionization detection as described below. Kinetic assays were conducted at $25^{\circ} \mathrm{C}$ in $1 \mathrm{~mL}$ of $25 \mathrm{mM}$ HEPES (pH 7.5) containing $100 \mu \mathrm{M} \mathrm{MnCl}$. Enzyme $(0.5-8 \mu \mathrm{M})$ was preincubated in the reaction buffer for $5 \mathrm{~min}$. Reactions were initiated by the addition of fosfomycin $(0.5-15 \mathrm{mM})$. After $10 \mathrm{~min}$, the reactions were quenched by the addition of 50 $\mu \mathrm{L}$ of chloroform, and the mixtures were vortexed and immediately placed on dry ice. The samples were then thawed, and tert-butylphosphonic acid was added as an internal standard at a final concentration of $8.1 \mathrm{mM}$. After centrifugation at $13000 \mathrm{~g}$ for $5 \mathrm{~min}, 200 \mu \mathrm{L}$ of the samples was placed in silanized glass tubes and taken to dryness via a speed vac. The dried samples were derivatized by the addition of $50 \mu \mathrm{L}$ of a 1:1:0.2 mixture of chloroform, bis(trimethylsilyl)acetamide, and trimethylchlorosilane. The tubes were then sealed and incubated at room temperature overnight. The samples were then injected onto a $0.25 \mathrm{~mm}$ (inside diameter) $\times 30 \mathrm{~m}$ RTX-1701 column attached to a Clarius 500 gas chromatograph equipped with a flame ionization detector. A linear temperature gradient (from 145 to $210{ }^{\circ} \mathrm{C}$, at a rate of $5{ }^{\circ} \mathrm{C} / \mathrm{min}$ ) at a constant carrier gas (He) flow rate of $1 \mathrm{~cm}^{3} / \mathrm{min}$ was used to elute the samples. The TMS derivatives of tert-butylphosphonic acid, fosfomycin, and 1,2-dihydroxypropylphosphonic acid eluted at $5.8,8.5$, and $13.3 \mathrm{~min}$, respectively. The concentration of product was determined using a plot of the area ratio of product to internal standard versus product concentration.

Generation of the E126Q Mutant of Fos $X^{\text {LMATCC. Site- }}$ directed mutagenesis was performed on the Imo1702ATCC: pET20b $(+)$ expression vector using the QuickChange sitedirected mutagenesis kit(Stratagene, La Jolla,CA). Oligonucleotide primers were designed to change codon 126 from GAA to CAG. The mutant expression plasmid was designated lmo1702ATCC(E126Q):pET20b(+). The mutation was confirmed by DNA sequencing, and the mutant protein was expressed and purified as previously described.

Protein Crystallization. The protein readily crystallizes in a variety of crystal forms depending on the $\mathrm{pH}$ and composition of the crystallization buffer. All crystallization experiments were conducted at $22{ }^{\circ} \mathrm{C}$ by the hanging-drop vapor-diffusion method. The details for the six crystal forms are as follows. For the monoclinic crystal (forms I and II), crystals were grown by mixing $1 \mu \mathrm{L}$ of the enzyme at 15.0 $\mathrm{mg} / \mathrm{mL}$ with $1 \mu \mathrm{L}$ of the reservoir solution $[18-20 \%(\mathrm{w} / \mathrm{v})$ polyethylene glycol 8000 and $0.1 \mathrm{M}$ sodium citrate (pH 5.75) for form I or ( $\mathrm{pH}$ 6.5) for form II, 4-12 mM sodium acetate and $10 \%$ glycerol]. For the hexagonal crystal form, crystals were obtained after mixing equal volumes of enzyme at 15 $\mathrm{mg} / \mathrm{mL}$ and the reservoir solution $[15 \%(\mathrm{w} / \mathrm{v})$ polyethylene glycol 8000, 0.1 M sodium citrate ( $\mathrm{pH} 5.6$ ), and $20 \mathrm{mM}$ sodium acetate]. For the tetragonal crystal form, crystals were obtained after mixing equal volumes of enzyme at $15 \mathrm{mg} /$ $\mathrm{mL}$ incubated with $12 \mathrm{mM} \mathrm{MnCl}$ and the reservoir solution [22\% PEG 3350, 0.1 M Tris (pH 8.1), 0.2 $\mathrm{M} \mathrm{MgCl}_{2}$, and $5 \%$ 2-propanol]. For the $\mathrm{FosX} \cdot \mathrm{Mn}(\mathrm{II}) \cdot \mathrm{SO}_{4}{ }^{2-}$ complex, crystals of the complex were obtained after mixing equal volumes of enzyme at $15 \mathrm{mg} / \mathrm{mL}$ incubated with $12 \mathrm{mM}$ $\mathrm{MnCl}_{2}$ and the reservoir solution [30\% PEG 8000, $50 \mathrm{mM}$ sodium cacodylate ( $\mathrm{pH}$ 6.5), and $0.1 \mathrm{M}$ ammonium sulfate]. 


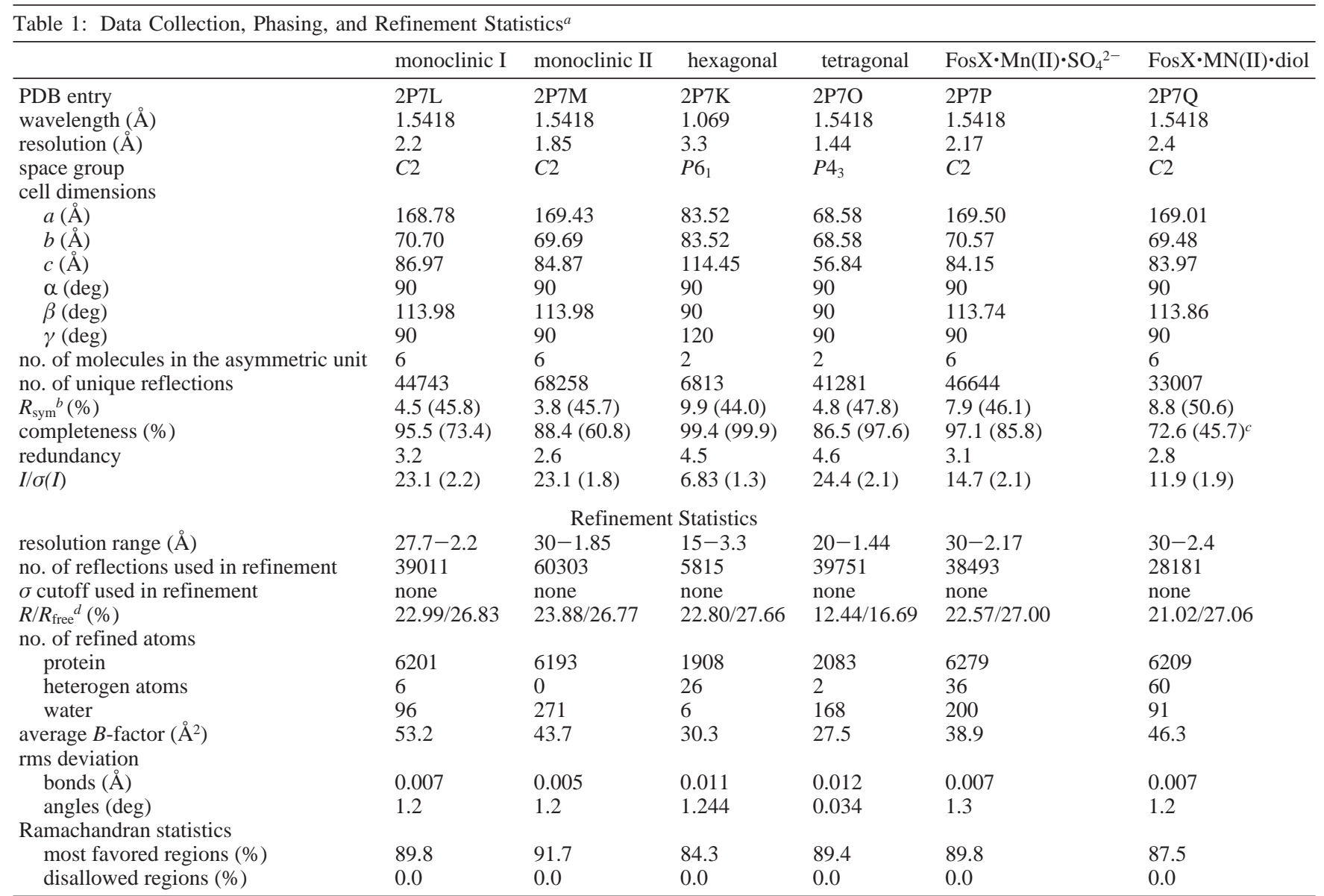

${ }^{a}$ Values in parentheses are for the highest-resolution shell. ${ }^{b} R_{\text {sym }}=\sum\left|I_{i}-\langle I\rangle\right| / \sum I_{i}$, where $I_{i}$ is the intensity of the $i$ th observation and $\langle I\rangle$ is the mean intensity of the reflection. ${ }^{c}$ This data set is $72.6 \%$ complete due to the fact that the crystal was highly mosaic, resulting in the rejection of a significant number of reflections during scaling (vida supra). ${ }^{d} R=\sum|| F_{\mathrm{o}}|-|\left|F_{\mathrm{c}}\right|\left|/ \sum\right| F_{\mathrm{o}} \mid$, where $F_{\mathrm{o}}$ and $F_{\mathrm{c}}$ are the observed and calculated structure factor amplitudes, respectively. $R_{\text {free }}$ is calculated using 4.9, 3.8, 4.8, 3.8, 3.5, and 3.5\% of reflections omitted from the refinement for the monoclinic I, monoclinic II, hexagonal, tetragonal, FosX $\cdot \mathrm{Mn}(\mathrm{II}) \cdot \mathrm{SO}_{4}{ }^{2-}$, and Fos $\mathrm{X} \cdot \mathrm{Mn}(\mathrm{II}) \cdot$ diol data sets, respectively. The same $R_{\text {free }} \mathrm{Set}$ from the monoclinic form II was used for the refinement of all monoclinic data sets because of their isomorphous character.

For the FosX(E126Q)・Mn(II)・diol complex, crystals of the product complex were obtained with the E126Q mutant protein by mixing equal volumes of enzyme at $15 \mathrm{mg} / \mathrm{mL}$ containing $12 \mathrm{mM} \mathrm{MnCl} 2,12 \mathrm{mM}$ diol, and the reservoir solution [18\% PEG 8000, 0.1 M sodium cacodylate ( $\mathrm{pH} 6.5$ ), $0.2 \mathrm{M}$ magnesium acetate, and 10\% glycerol].

Data Collection. Diffraction data of the hexagonal crystal form were collected at $100 \mathrm{~K}$ at the PX station at the Center for Advanced Microstructures and Devices at Louisiana State University with a MAR charge-coupled device camera. Data for all other crystal forms were collected at $100 \mathrm{~K}$ with a cryo-stream cooler from Oxford Cryosystems with a $345 \mathrm{~mm}$ MAR Research imaging plate detector mounted on a NONIUS FR591 rotating anode generator ( $\mathrm{Cu} \mathrm{K} \alpha$ radiation). Data were processed with DENZO and scaled using Scalepack (21). Data collection and data processing statistics are given in Table 1.

Crystal Structure Determination. The structure of the hexagonal crystal form was determined by the molecular replacement (MR) procedure as implemented in AMORE (22). A dimer of M. loti FosX (PDB entry 1R9C), its sequence being $56 \%$ identical to that of the target protein, was used as a search model. MR solutions for all other crystal structures were located by using the refined structure of the hexagonal form of the protein. The positioned MR models were refined using the maximum likelihood refinement in REFMAC (22) (hexagonal form), SHELX (tetragonal form), or CNS (23) (all monoclinic data sets). Bulk solvent correction was applied in each case, and strict NCS constraints were applied for the low-resolution hexagonal form. In all other crystal structures, no NCS constraints were used due to the high resolution of the data and significant differences between conformations of independent molecules. O (24) was used to build the initial models, as well as throughout the refinement. Refinement statistics are given in Table 1. Details of refinement of each particular structure follow.

Monoclinic Form I (2.2 A resolution). The asymmetric unit, as in all monoclinic Listeria FosX crystal forms, is comprised of three dimers. No significant electron density was observed for residues 35-39 and 131-133 of monomer A, 97-102, 132, and 133 of monomer B, 130-133 of monomer C, 35-41 of monomer D, and 131-133 of both monomers $\mathrm{E}$ and $\mathrm{F}$, an indication that these regions are highly mobile or disordered. Electron density in the $F_{\mathrm{o}}-F_{\mathrm{c}}$ map which can be attributed to a glycerol molecule was found in the active site of monomer A; 96 water molecules were built into the electron density proximal to hydrogen bonding partners. Alternate conformations were identified for residues N24 (monomer C) and C55 (monomer E). 
Monoclinic Form II (1.85 ^ resolution). The final model consists of residues 1-34 and 39-131 (molecule A), 1-94 and 103-130 (molecule B), 1-129 (molecule C), 1-36 and 43-131 (molecule D), 1-128 (molecule E), and 1-130 (molecule F) and 271 water molecules. Alternate conformations were built for E29 and C55 (molecule B), C55 (molecule C), K13 and C55 (molecule D), C55 (molecule E), and C55 (molecule F).

Hexagonal Form ( $3.3 \AA$ resolution). The final model consists of residues $1-33$ and $41-128$ of both monomers and six water molecules. A difference Fourier map suggested the presence of a citrate molecule in the active site of the protein. No electron density was found that could be associated with the presence of $\mathrm{Mn}(\mathrm{II})$.

Tetragonal Form (1.44 A resolution). This crystal form was merohedrally twinned with an almost perfect twinning fraction of 0.498 . The asymmetric unit is comprised of one dimer. The structure was anisotropically refined due to the high-resolution data. There is no electron density for residues A33-A37, A133, B33-B37, B132, and B133. Difference electron density confirmed that the active site of the protein contains $\mathrm{Mn}$ (II). One hundred sixty-eight water molecules were located. Residues A24, A43, A56, A78, B24, B27, and B56 were modeled in two alternate conformations.

Fos $\mathrm{X} \cdot \mathrm{Mn}(\mathrm{II}) \cdot \mathrm{SO}_{4}{ }^{2-}$ Complex $(2.17 \AA$ resolution $)$. The final model consists of residues 1-131 (monomer A), 1-95 and 103-129 (monomer B), 1-131 (monomer C), 1-34 and 42-132 (monomer D), 1-131 (monomer E), and 1-131 (monomer F), six $\mathrm{Mn}^{2+}$ cations, six sulfate ions, and 200 water molecules. The $\mathrm{C} 55$ residues (monomers $\mathrm{C}-\mathrm{F}$ ) were modeled in two alternate conformations.

Fos $X(E 126 Q) \cdot M n(I I) \cdot$ Diol Complex $(2.4$ A resolution). Two data sets were collected: one to $2.8 \AA$ resolution with 97\% completeness and a second one to $2.4 \AA$ with $72.6 \%$ completeness. Difference Fourier from both data sets clearly established the position and orientation of the diol in the active site. Full refinement was performed with the higherresolution data set since the presence of six copies of the protein molecule in the asymmetric unit compensates, in part, for the incompleteness of the $2.4 \AA$ data. The final model consists of residues 1-130 (monomer A), 1-95 and 103129 (monomer B), 1-100 and 104-129 (monomer C), 1-35 and 42-132 (monomer D), 1-131 (monomer E), and 1-131 (monomer F), six $\mathrm{Mn}^{2+}$ cations, six diol molecules, and 91 water molecules. The diol product of the reaction was identified in the active site on the basis of strong electron density in the difference Fourier map. Residue C55 of monomer $\mathrm{E}$ was observed in two alternate conformations.

The refined coordinates for all six structures have been deposited in the Protein Data Bank with the entries given in Table 1.

\section{RESULTS}

Characterization of a Naturally Occurring Mutant of FosX from L. monocytogenes. The PCR-based cloning of the lmo1702 gene from L. monocytogenes genomic DNA obtained from American Type Culture Collection led to an unanticipated result. DNA sequencing of the expression plasmid containing the cloned lmo1702 gene revealed 31 nucleotide differences in the sequence when compared to the deposited sequence for the same gene from L. monocy-

\begin{tabular}{lcc}
\hline Table 2: Steady State Kinetic Parameters for & FosX and Its Mutants \\
\hline enzyme & $k_{\text {cat }}\left(\mathrm{s}^{-1}\right)$ & $k_{\text {cat }} / K_{\mathrm{M}}\left(\mathrm{M}^{-1} \mathrm{~s}^{-1}\right)$ \\
\hline FosX $^{\mathrm{LMEGD} a}$ & $34 \pm 2$ & $(9 \pm 2) \times 10^{4}$ \\
E44G $^{a}$ & $<0.00004$ & - \\
FosX & $52 \pm 3$ & $(7 \pm 2) \times 10^{4}$ \\
E126Q & $51 \pm 2$ & $(4.3 \pm 0.2) \times 10^{4}$ \\
E44D & $0.094 \pm 0.002$ & $63 \pm 5$ \\
E44T & $0.011 \pm 0.004$ & $0.26 \pm 0.2$ \\
E44A & $<0.00004$ & - \\
FosX & $0.015 \pm 0.002$ & $(5.0 \pm 0.6) \times 10^{2}$ \\
\hline${ }^{a}$ Previously reported by Fillgrove et al. (17).
\end{tabular}

togenes strain EGD (25) (Figure S1 of the Supporting Information). Repeated PCR amplifications yielded a gene containing these same 31 nucleotide mutations. Translational analysis of this mutant gene indicated that no new stop codons had been introduced and that the gene still encoded a 133-amino acid polypeptide. While some of the nucleotide mutations were silent, others resulted in the following 10 amino acid mutations in the published protein sequence: T20A，R23Q，E24N，Q37K，Q65R，R73Q，I83T，S88A, I93M, and E101Q. Hence, this naturally occurring mutant gene has been named lmo1702ATCC to distinguish it from the gene from which the published sequence (lmo1702EGD) was obtained. One unique aspect of the lmo1702ATCC gene is the fact that it encodes a FosX that is readily crystallized to produce diffraction quality crystals under a variety of crystallization conditions. In contrast, the protein encoded by the lmo1702EGD gene (Fos $\mathrm{X}^{\mathrm{LMEGD}}$ ) could not be coaxed to crystallize under more than 1400 experimental conditions.

Purification and Properties of Fos $X^{\text {LMATCC. The expression }}$ of $l m o 1702 \mathrm{ATCC}$ in E. coli BL21(DE3) cells was quite poor. Codon usage analysis of the lmo1702ATCC gene indicated that $\sim 10 \%$ were rare codons in E. coli. Utilization of $E$. coli Rosetta(DE3) cells dramatically improved protein expression where typical yields of pure protein were $30-40 \mathrm{mg} / \mathrm{L}$ of culture. The MALDI-MS analysis of the enzyme gave a molecular mass of $15568 \mathrm{Da}$, which is in good agreement with the calculated mass of $15570 \mathrm{Da}$. A survey of divalent cation activation of the enzyme confirmed that Mn(II) was still the preferred metal ion (17). The protein, as Fos $X^{\mathrm{LMEGD}}$ does, confers robust resistance (MIC $>25 \mathrm{mg} / \mathrm{mL}$ ) to fosfomycin in the biological context of $E$. coli . In the absence of the enzyme, E. coli is very sensitive to fosfomycin (MIC $<0.025 \mathrm{mg} / \mathrm{mL}$ ). The catalytic efficiency of FosX ${ }^{\mathrm{LMATCC}}$ is equivalent to that of Fos $X^{\text {LMEGD }}$ (17), suggesting that none of the 10 mutated amino acids has a dramatic effect on catalysis (Table 2).

Determination of the Stereochemical Configuration at C1 of the Diol Product. The FosX enzymes catalyze the addition of a solvent-derived oxygen atom to $\mathrm{C} 1$ of fosfomycin. The ring opening reaction preserves the $S$ configuration at $\mathrm{C} 2$, but the configuration at $\mathrm{C} 1$ is unclear. The $\mathrm{C} 1$ center can adopt either the $R$ or $S$ configuration, resulting in either of two possible products, $(1 S, 2 S)-\mathbf{4}$ or $(1 R, 2 S)-\mathbf{4}$ (Scheme 2). To distinguish between the two possible products generated by the FosX enzymes, the phenylboronate ester derivative of the vicinal diol product was prepared and analyzed by NOESY NMR. The ester should be either 5 or $\mathbf{6}$ (Scheme 2) depending on the configuration at $\mathrm{C} 1$ of $\mathbf{4}$.

The derivatization reaction was complete within $30 \mathrm{~min}$ of mixing phenylboronic acid with $\mathbf{4}$ in water at $\mathrm{pH}$ 8.5. The 


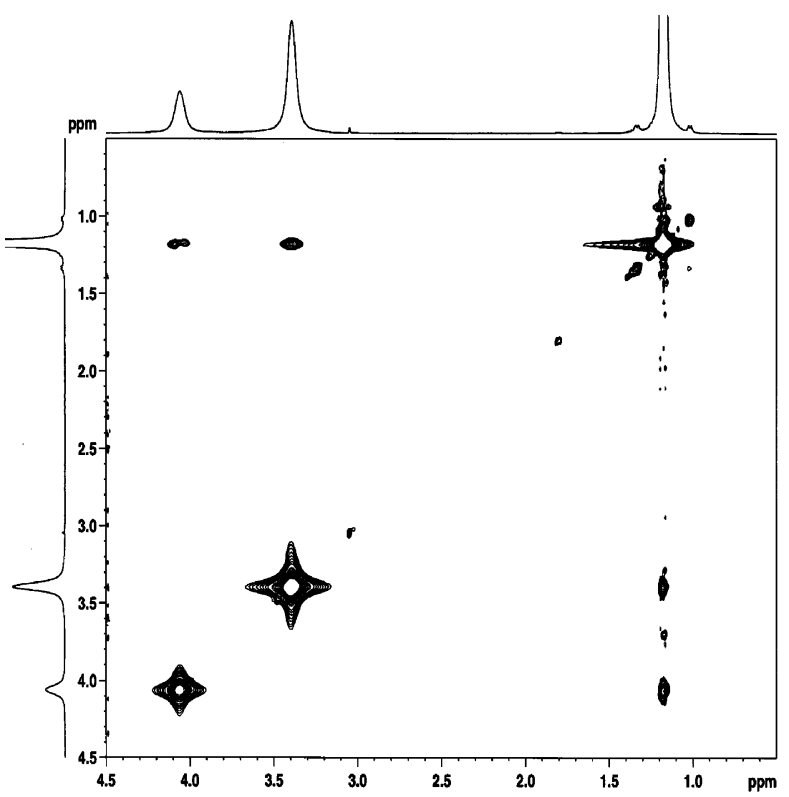

FIGURE 1: Region from 4.5 to $0.5 \mathrm{ppm}$ of the NOESY ${ }^{1} \mathrm{H}$ NMR spectrum of the phenylboronic ester of $\mathbf{4}$. A cross-peak is observed between the $\mathrm{C} 1$ proton resonance at $4.05 \mathrm{ppm}$ and the $\mathrm{C} 3$ methyl proton resonance at $1.15 \mathrm{ppm}$. The presence of this cross-peak and the absence of a cross-peak between the $\mathrm{C} 1$ proton resonance and the $\mathrm{C} 2$ proton resonance at $3.38 \mathrm{ppm}$ indicate that the $\mathrm{C} 1$ center has the $S$ configuration.

${ }^{1} \mathrm{H}$ NMR spectrum (Figure 1) confirmed the formation of the boronate ester complex where the splitting patterns for the protons on $\mathrm{C} 1$ and $\mathrm{C} 2$ of the free diol, at 3.38 and 4.05 ppm, respectively (Figure S2 of the Supporting Information), had collapsed from multiplets to broad singlets due to coupling to the ${ }^{10} \mathrm{~B}$ and ${ }^{11} \mathrm{~B}$ nuclei of the ester. The virtue of using phenylboronic acid to form the boronate ester complex was that the ${ }^{1} \mathrm{H}$ resonances of the phenyl ring are downfield from the ${ }^{1} \mathrm{H}$ resonances of the diol moiety, allowing for the easy assignments of NOEs. The NOESY NMR spectrum of the boronate ester complex is shown in Figure 1. We anticipated that a NOE would be observed between the neighboring $\mathrm{C} 2$ and methyl protons for either product configuration. The presence of a NOE between the $\mathrm{C} 1$ proton and methyl protons in conjunction with the absence of a NOE between the $\mathrm{C} 1$ and $\mathrm{C} 2$ protons demonstrates that the boronate ester is $\mathbf{6}$ and the FosX diol product is $(1 S, 2 S)-\mathbf{4}$. The NOESY NMR spectrum of the underivatized diol exhibits NOEs between both the $\mathrm{C} 1$ and $\mathrm{C} 2$ protons and between the $\mathrm{C} 1$ and methyl protons as a consequence of free rotation about the $\mathrm{C} 1-\mathrm{C} 2$ bond (Figure $\mathrm{S} 2$ of the Supporting Information).

Structure of Fos $X^{L M A T C C}$ with Mn(II) and $\mathrm{SO}_{4}{ }^{2-}$ Bound. The structure of FosX (Figure 2) is remarkably similar to that of FosX $\mathrm{X}^{\mathrm{ML}}$ from M. loti (17) and to that of the FosA enzymes from Pseudomonas aeruginosa (FosA $\left.{ }^{\mathrm{PA}}\right)(18)$ and from transposon Tn2921 (FosA ${ }^{\mathrm{TN}}$ ) (26). This homodimeric enzyme is in a domain-swapped arrangement where $\mathrm{H} 7$ of one subunit joins H69 and E118 from the opposite subunit to form the divalent metal ion-binding site. The average ligand-metal distances in the six active sites for $\mathrm{H} 7(2.3$ $\AA), H 69(2.4 \AA)$, E118 (2.2 ̊), and the sulfate oxygen $(2.2$ $\AA)$ are reasonable. The hydroxyl group of T9 is within hydrogen bonding distance of one of the sulfate oxygens ( 2.8 $\AA$, averaged over all six active sites). The cup-shaped metal-

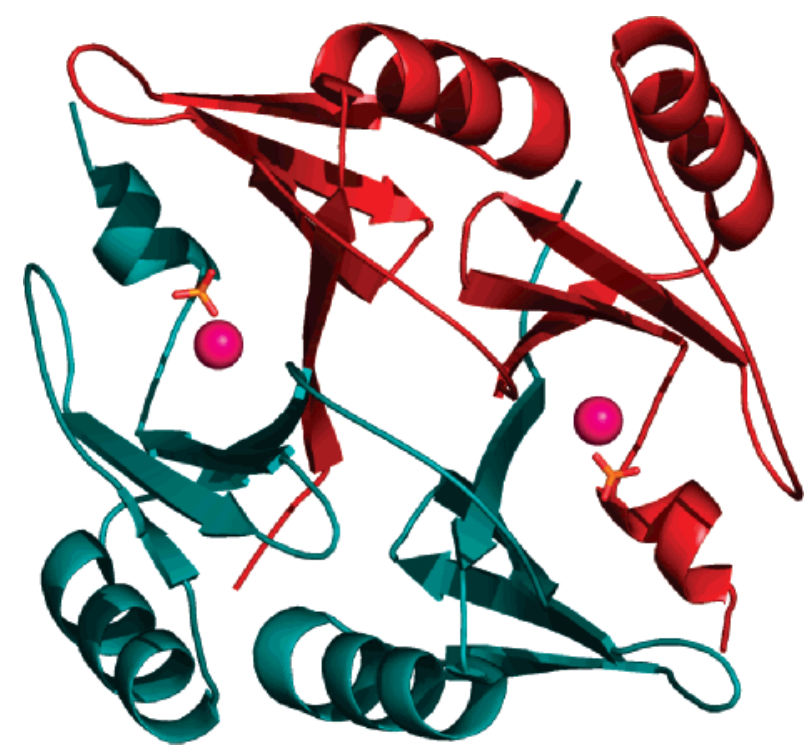

FIGURE 2: Ribbon diagram of the Fos $X^{\text {LMATCC }}$ dimer containing $\mathrm{Mn}(\mathrm{II})$ with the two subunits colored red and teal. The Mn(II) ions are colored magenta, and the sulfate ions are depicted as sticks. The image was generated using PYMOL (29).

binding site is formed by paired $\beta \alpha \beta \beta \beta$ motifs as observed with other fosfomycin resistance proteins and members of the VOC superfamily $(27,28)$. The position of the bound sulfate ion is of particular interest since it is expected to be a good indicator of the position of the phosphonate group in the substrate or product complexes.

Comparison with the Structures of the Apoenzyme. As was the case with the FosA ${ }^{\mathrm{TN}}$ enzyme from transposon Tn2921 (26), the use of citrate buffer and low $\mathrm{pH}$ in crystallization experiments prevents binding of the $\mathrm{Mn}(\mathrm{II})$ cation in the active site of the protein. Varying the $\mathrm{pH}$ of the citrate buffer yielded several apo structures of Fos $X^{\text {LMATCC }}$, including monoclinic form I ( $\mathrm{pH}$ 5.75) and form II (pH 6.5) and a hexagonal crystal form ( $\mathrm{pH}$ 5.6). Both monoclinic crystal forms are isostructural with three dimers in the asymmetric unit. Superposition of these structures indicated that the $\mathrm{A}-\mathrm{B}$ dimers are quite similar with a 0.534 $\AA$ rmsd for 245 equiv $\mathrm{CA}$ atoms, while $\mathrm{C}-\mathrm{D}$ and $\mathrm{E}-\mathrm{F}$ dimers exhibit alternate orientations of the loops between residues 34-43 and 94-103.

Structure of Fos X(E126Q) with Bound Product. Crystallization trials with the E126Q mutant of Fos $X^{\text {LMATCC }}$ in the presence of the product $(1 S, 2 S)-\mathbf{4}$ resulted in crystals containing the diol bound in the active site. The structure was determined at a resolution of $2.4 \AA$. The electron density for the product is quite clear (Figure $3 \mathrm{~A}$ ). The chirality of the diol product observed in the structure agrees with the stereochemical assignment determined by NMR. The product binds to the active site with numerous interactions (Figure 3). Primary interactions with the $\mathrm{Mn}$ (II) center include one of the phosphonate oxygens and the $\mathrm{C} 2 \mathrm{OH}$ group of the product with bond distances averaged over the six active sites of $2.1 \AA$ for both. The coordination geometry about the metal is best described as square pyramidal with H69, E118, and the product in the pyramidal plane and $\mathrm{H} 7$ perched in the apical position (Figure 3B). There are also several potential hydrogen bonding interactions with the diol (Figure 3C), although not all interactions are found in every active site. For example, the $\mathrm{C} 2 \mathrm{OH}$ group is within hydrogen bonding 

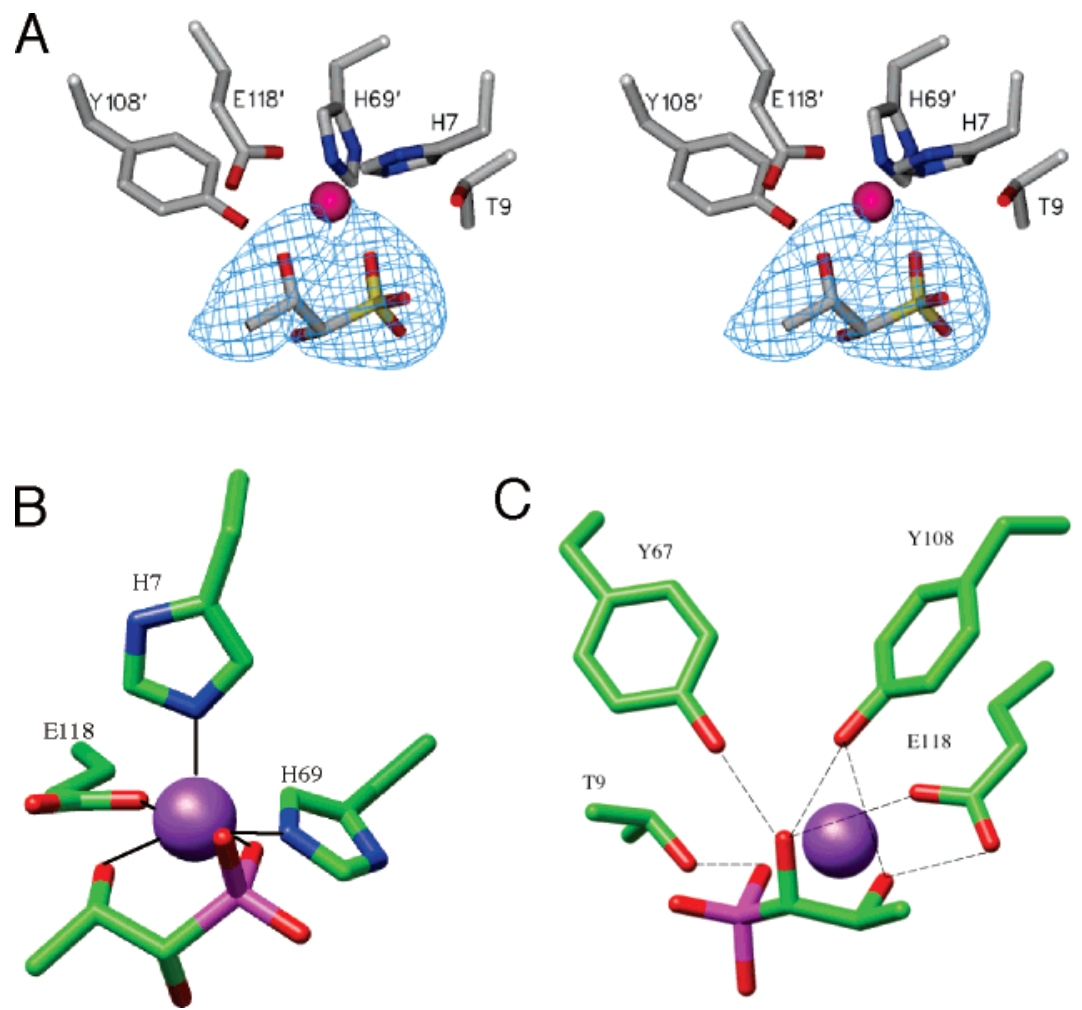

FIgURE 3: Active site of Fos $X^{\text {LMATCC }}$ with the product $(1 S, 2 S)-\mathbf{4}$ bound. (A) Stereoview of the electron density $F_{\mathrm{o}}-F_{\mathrm{c}}$ simulated annealed omit map at a resolution of $2.4 \AA$ with the omitted product molecule contoured at $4 \sigma$. Metal ligands H7, H69', and E118' as well as residues Y108' and T9 that participate in the binding of the product are shown. (B) Square pyramidal coordination geometry of the metal ion with $\mathrm{H} 7$ in the apical position. The metal-ligand interactions are denoted with solid lines. (C) Composite of the possible hydrogen bonds observed in the six active sites denoted with dotted lines.

distance $(2.9 \AA$, averaged over five active sites) of the carboxylate oxygen of E118 that is not coordinated to the $\mathrm{Mn}(\mathrm{II})$. The $\mathrm{C} 2 \mathrm{OH}$ group is also within hydrogen bonding distance of the side chain $\mathrm{OH}$ group of Y108 (2.8 ̊̊ averaged over six active sites). The $\mathrm{OH}$ group at $\mathrm{C} 1$ of the diol is within hydrogen bonding distance of the $\mathrm{OH}$ groups of both Y67 (2.7 A, averaged over four active sites) and Y108 (2.9 $\AA$, averaged over four active sites) and the carboxylate of E118 that is coordinated to the metal $(2.8 \AA$, averaged over four active sites). Finally, there is also potential hydrogen bonding between one of the phosphonate oxygens and the OH group of T9 (2.9 $\AA$ ) averaged over six active sites. A summary of all observed interactions with the product bound in the active sites is given in Figure 3C.

Identification of an Unusual Conformation of the $C$ Terminal Tail. The high-resolution structure of the tetragonal crystal form of FosX exhibited a unique orientation of the C-terminal tail that is not observed in any of the other FosX structures. While the $\mathrm{C}$-terminal tail is typically a helix that extends away from the active site, in this structure, the tail loops back into the active site where a carboxylate oxygen of E126 directly coordinates with the Mn(II) center at a distance of $2.15 \AA$ averaged over the two active sites (Figure 4B). The E126 carboxylate is also within hydrogen bonding distance of the side chain $\mathrm{OH}$ group of T9 (Figure 4). A superposition of this structure with the structure containing $\mathbf{4}$ shows that the phosphonate of $\mathbf{4}$ and the carboxylate of E126 occupy the same space (Figure 4B) where an oxygen atom from each coordinates to the $\mathrm{Mn}$ (II) center. In addition, a water molecule is also observed bound to the $\mathrm{Mn}(\mathrm{II})$ at a distance of $2.24 \AA$ averaged over the two active sites. The five-coordinate geometry of the $\mathrm{Mn}$ (II) is square pyramidal and very similar to the geometry of the product complex with $\mathrm{H} 7$ in the apical position (compare Figure 3B with Figure 4C).

The question of whether this structure represents a dominant conformation in solution or an artifact imposed by crystal packing arises. If the protein adopts this conformation in solution to a significant extent, the C-terminal tail would be expected to inhibit enzyme activity by partially occupying the fosfomycin binding site. To test this hypothesis, the steady state kinetic parameters of the E126Q mutant (the mutant used to obtain the structure of the product complex) were determined (Table 2). It is expected that with glutamine in position 126, the mutant would have a weaker tendency to form a complex with the Mn(II) center. Although there is a small decrease in the $k_{\mathrm{cat}} / K_{\mathrm{M}}$ for the mutant enzyme (Table 2), the results indicate that the observed conformation of the tail in the tetragonal crystal form is probably not the dominant conformation in solution.

Role of E44 in Catalysis. The previous structural analysis of the active site structure of Fos $\mathrm{X}^{\mathrm{ML}}$ suggested that E44 acts as a general base in the addition of water to the antibiotic while the $\mathrm{Mn}$ (II) center provides electrophilic assistance and T9 supplies a proton (Figure 5). Indeed, the E44G mutant of FosX $\mathrm{X}^{\mathrm{ML}}$ exhibited a substantially reduced catalytic activity (17). The same mutation in Fos $X^{\mathrm{LMEGD}}$ (an enzyme with an efficiency much higher than that of Fos $\mathrm{X}^{\mathrm{ML}}$ ) produced a protein with no detectable activity, suggesting that the mutant might be structurally compromised and therefore catalytically defective. In this context, the role of E44 in the reaction was investigated further. The E44A mutant of FosX $\mathrm{X}^{\mathrm{LMATCC}}$ was also essentially inactive as a catalyst, a result consistent with a structurally compromised enzyme. In contrast, the more 


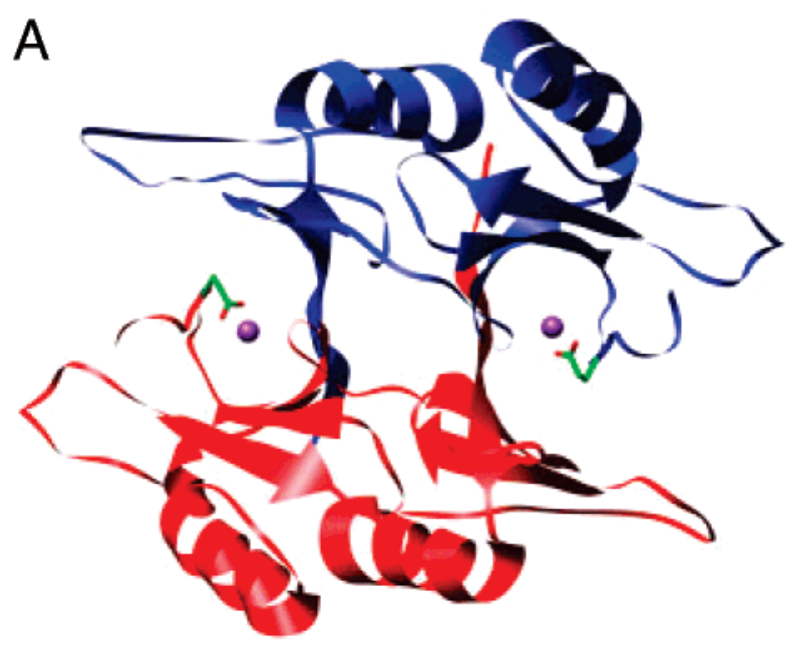

B
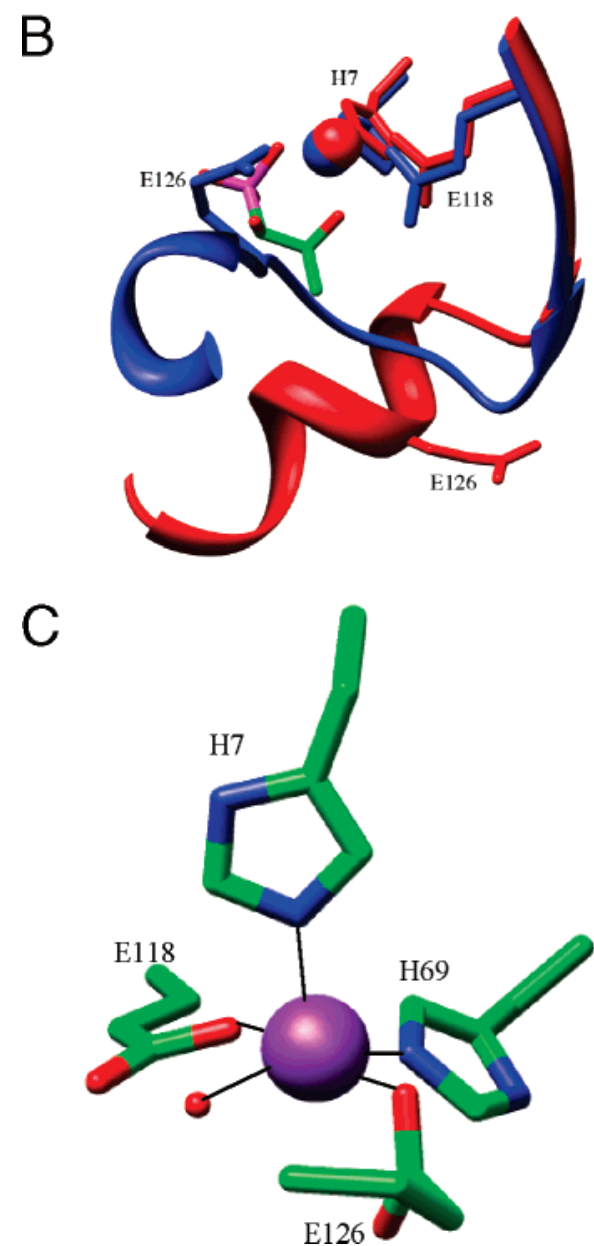

FiguRE 4: (A) Ribbon diagram of the FosX dimer of the tetragonal crystal form. The two subunits are colored red and blue. The Mn(II) ions are colored purple. The C-terminal tail has adopted an orientation allowing E126 to coordinate the $\mathrm{Mn}$ (II) ion. (B) Superposition of the high-pH tetragonal crystal form and FosX structure with the product bound. The superposition was generated using the positions of $\mathrm{T} 9$, the metal ion, and the metal ligands $\mathrm{H} 7$, H69, and E118. The T9 and H69 residues are not shown for clarity. The tetragonal structure is colored blue, while the structure of FosX with product bound is colored red. (C) Square pyramidal coordination geometry about the metal with $\mathrm{H} 7$ in the apical position.

conservative mutants, E44D and E44T, expressed well, were isolable and had easily detectable, though much reduced, catalytic activity (Table 2 ). These results are consistent with the proposed role of E44 acting as a general base in the

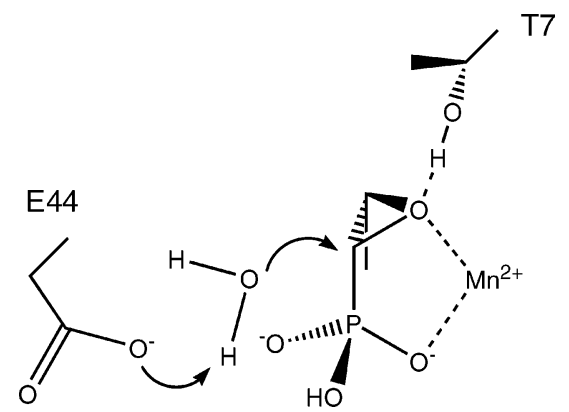

FIGURE 5: Proposed participation of E44 as a general base in the catalytic mechanism of FosX (17). The distance between the carboxylate of $\mathrm{E} 44$ and $\mathrm{C} 1$ of fosfomycin is estimated to be between 5 and $6 \AA .2$

addition of water to the epoxide. The most conservative mutation (E44D) exhibits a catalytic efficiency that is reduced by a factor of $\sim 1100$, a magnitude that is consistent with E44 acting as a general base in the addition of water.

\section{DISCUSSION}

Mechanism and Stereochemical Course of the FosXCatalyzed Reaction. Previous work has established that the regiochemistry of the FosX-catalyzed reaction involves addition of water at $\mathrm{C} 1$ of the antibiotic (17). The carboxylate of E44 is located in a position that is estimated to be $\sim 5-6$ $\AA$ from $\mathrm{C} 1$ of bound fosfomycin, a location that is consistent with E44 acting as a general base in the addition of water to the epoxide (Figure 5). Many microbial and mammalian epoxide hydrolases use a carboxylate to form an alkylenzyme intermediate that is subsequently hydrolyzed (30). However, single-turnover experiments with both Fos $\mathrm{X}^{\mathrm{ML}}$ and Fos $X^{\text {LMEGD }}$ are consistent with the direct addition of water to the epoxide (17). Analogous to the proposed mechanism of FosA, the metal ion is presumed to act as an acid catalyst by interacting with the oxirane oxygen. Acid-catalyzed hydration of epoxides can occur by direct $\mathrm{S}_{\mathrm{N}} 2$ addition of water with inversion of configuration at the oxirane carbon or via a carbocation intermediate with either mixed stereochemistry or retention of configuration (31). That the FosX reaction product, $\mathbf{4}$, is now known to be $(1 S, 2 S)-1,2$ dihydroxypropylphosphonic acid shows that the stereochemical course of the FosX-catalyzed reaction proceeds with inversion of configuration by direct $\mathrm{S}_{\mathrm{N}} 2$ attack of an activated water molecule at $\mathrm{C} 1$ of fosfomycin. The observed reaction mechanism proceeds in a manner similar to that proposed for FosA where nucleophilic addition occurs $\alpha$ to the phosphonate with inversion of configuration (32).

Insights into Substrate Binding. The identification of a naturally occurring mutant of the Listeria FosX (lmo1702ATCC) had a major impact on this work. This mutant enzyme crystallized readily under multiple conditions. Analysis of the FosX structures reveals that each amino acid mutation was located either on the surface of the protein or in a region with high solvent accessibility away from the active site. Most importantly, the structure of the product complex with

${ }^{2}$ The distance of $5.1 \AA$ between the carboxylate of E44 and C1 of the substrate is based on a model of the substrate complex. The distance between $\mathrm{E} 44$ and $\mathrm{C} 1$ of the diol product is $5.9 \pm 0.3 \AA$ (averaged over the six active sites). From these results, we conclude that E44 is probably between 5 and $6 \mathrm{~A}$ from $\mathrm{C} 1$ in the actual substrate complex. 


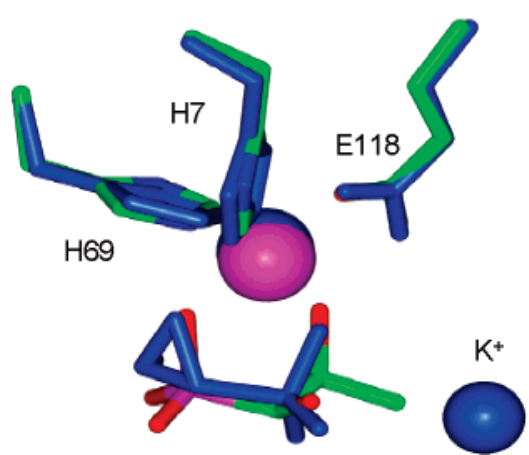

FIGURE 6: Local superposition of the FosX(E126Q) $\cdot \mathrm{Mn}(\mathrm{II}) \cdot 4$ complex (colored) with the $P$. aeruginosa FosA $\cdot \mathrm{Mn}(\mathrm{II}) \cdot \mathbf{1}$ complex (blue). The overlay illustrates the different positions of the phosphonate groups observed in the FosX and FosA structures. The potential electrostatic interactions between the $\mathrm{K}^{+}$ion (blue sphere) in the FosA structure and the phosphonate of $\mathbf{1}$ could result in this difference in binding orientation. The superposition was generated using the positions of the metal and conserved metal ligands $\mathrm{H} 7$, H69, and E118.

the FosX(E126Q) mutant provided surprising new insight into how the FosX enzyme might bind the substrate.

The high-resolution structure of Fos $\mathrm{A}^{\mathrm{PA}}$ in the presence of the substrate $\mathbf{1}$ provided a detailed look at the interactions between the protein and the metal and the orientation of the substrate in the active site (18). Extrapolation of this structure to that of FosX initially suggested a specific mechanism for the hydration reaction involving E44 as a general base (Figure 5) (17). Surprisingly, the structure of the product complex, FosX $\cdot \mathrm{Mn}(\mathrm{II}) \cdot \mathbf{4}$, indicates that the phosphonate group is oriented $\sim 180^{\circ}$ from the phosphonate group in the substrate complex of FosA ${ }^{\mathrm{PA}}$. In contrast to the observed orientation of fosfomycin bound in the active site of FosA $\mathrm{A}^{\mathrm{PA}}$ (18), the phosphonate of $\mathbf{4}$ bound to Fos $\mathrm{X}$ is oriented away from the potassium ion in FosA as illustrated in Figure 6. The close superposition of the Mn(II) ligands for both structures indicates that the binding of $\mathbf{4}$ in this new orientation is not result of an altered $\mathrm{Mn}$ (II) binding site. Additional evidence supporting this unpredicted orientation of substrate and product binding may be found in the $\mathrm{E} \cdot \mathrm{Mn}(\mathrm{II}) \cdot \mathrm{SO}_{4}{ }^{2-}$ structure and the structure with the Cterminal tail in the active site. The superposition of the FosX $\mathrm{Mn}(\mathrm{II}) \cdot \mathbf{4}$ and $\mathrm{FosX} \cdot \mathrm{Mn}(\mathrm{II}) \cdot \mathrm{SO}_{4}{ }^{2-}$ structures (data not shown) indicates that the sulfate binds in the same position of the phosphonate of 4. Likewise, a carboxylate oxygen of El26 is observed coordinating to the $\mathrm{Mn}(\mathrm{II})$ center and results in the carboxylate occupying the same space as the phosphonate of $\mathbf{4}$ in the superimposed structures (Figure 4B).

The structural evidence suggests a very strong propensity for binding an anion (phosphonate) in the FosX enzyme that is different from the phosphonate orientation observed in the FosA-fosfomycin complex. The functional implication is that the substrate is bound in opposite orientations in FosA and FosX. One possible reason for the difference in orientation is that FosA contains a $\mathrm{K}^{+}$ion-binding site near the active site that has been proposed to guide the orientation of fosfomycin in the substrate complex. The FosX enzymes have no such binding site and no dependence on monovalent cations. An alternative, trivial, explanation is that the preferred orientation of the product in the FosX enzyme simply does not represent the binding geometry of the

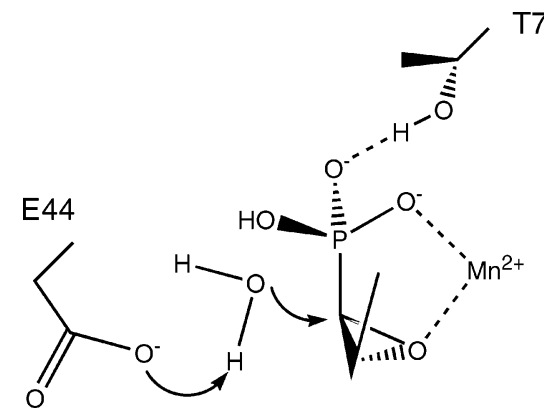

FIGURE 7: Orientation of E44 with respect to fosfomycin bound in the opposite orientation in the active site of Fos $\mathrm{X}^{\mathrm{LM}}$. The distance between the carboxylate of E44 and $\mathrm{C} 1$ of fosfomycin in the modeled complex is $5.1 \AA$. Note the difference in the potential role of T7 in the reaction compared to Figure 5 where the substrate is bound in the alternate orientation.

substrate. The current experimental evidence cannot strictly rule out this possibility.

Inasmuch as the role of E44 as a participant in catalysis was inferred from the orientation of the substrate seen in the structure of Fos $\mathrm{A}^{\mathrm{PA}}$, it is fair to ask whether this residue is in an appropriate position to act as a general base if the substrate binds in the opposite orientation. A quick modeling exercise with the substrate and the Fos $\mathrm{X}^{\mathrm{LMATCC}}$ structure indicates that E44 could play the same role in catalysis in either orientation as indicated in Figure 7. The carboxylate is still between 5 and $6 \AA$ from the backside of $\mathrm{C} 1$ with room for a water molecule between it and the substrate. ${ }^{2}$ However, the hydroxyl group of T9 now serves as an anchor for the phosphonate rather than for protonation of the oxirane oxygen as suggested previously in Figure 5.

Comparison of Fos $X^{M L}$ and Fos $X^{L M}$. The Fos $X^{\mathrm{ML}}$ enzyme was the first protein described to have fosfomycin hydrolase activity. However, that activity is quite low (Table 2), and the protein does not confer significant resistance to fosfomycin in E. coli (MIC $\leq 0.025 \mathrm{mg} / \mathrm{mL}$ ). The gene encoding Fos $\mathrm{X}^{\mathrm{ML}}$ is located in a phn operon of $M$. loti, an operon presumed to be involved in the transport and utilization of phosphonates. From these observations, we have concluded that Fos $\mathrm{X}^{\mathrm{ML}}$ is not a fosfomycin resistance protein but is an evolutionarily related protein that plays some yet to be identified role in the catabolism of phosphonates.

The Fos $\mathrm{X}^{\mathrm{ML}}$ and Fos $\mathrm{X}^{\mathrm{LM}}$ proteins are closely related structurally with a root-mean-square deviation (rmsd) on CA atoms of $0.789 \AA$ (Figure 8). However, the structural differences that determine whether one enzyme is a fosfomycin resistance protein are not obvious. The structures of the active site are virtually identical except for differences in the loops leading into the metal-binding site. It seems likely that differences in the loop structures may account, at least indirectly, for the differences in catalytic efficiency.

Conclusions. The FosX enzyme encoded in the genome of $L$. monocytogenes catalyzes the addition of water to the $\mathrm{C} 1$ position of the antibiotic with inversion of configuration. The results suggest that both the EGD and ATCC strains of the bacterium have an intrinsic resistance to the antibiotic provided by the Fos X enzyme.

\section{SUPPORTING INFORMATION AVAILABLE}

DNA sequence and translation of the lmo1702ATCC gene (Figure S1) and the NOSEY NMR spectrum of $(1 S, 2 S)-1,2-$ dihydroxypropylphosphonic acid, 4 (Figure S2). This material 


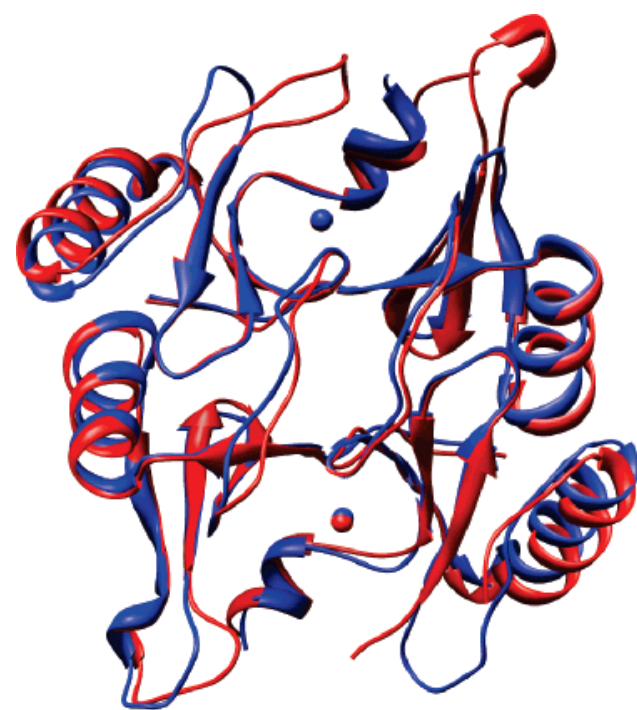

FIGURE 8: Global structural superposition of the CA atoms of the Fos $\mathrm{X}^{\mathrm{ML}}$ and Fos $\mathrm{X}^{\mathrm{LMATCC}}$ enzymes. The Fos $\mathrm{X}^{\mathrm{LMATCC}}$ structure used for the superposition was that of the $\mathrm{FosX} \cdot \mathrm{Mn}(\mathrm{II}) \cdot \mathrm{SO}_{4}{ }^{2-}$. The principal differences lie in the loops. The structural superposition was achieved with CHIMERA (33).

is available free of charge via the Internet at http:// pubs.acs.org.

\section{REFERENCES}

1. Walsh, C. (2000) Molecular mechanisms that confer antibacterial drug resistance, Nature 406, 775-781.

2. Hendlin, D., Stapley, E. O., Jackson, M., Wallick, H., Miller, A K., Wolf, F. J., Miller, T. W., Chaiet, L., Kahan, F. M., Flotz, E. L., Woodruff, H. B., Mata, J. M., Hernandez, S., and Mochales, S. (1969) Phosphonomycin, a new antibiotic produced by strains of Streptomyces, Science 166, 122-123.

3. Christensen, B. G., Leanza, W. J., Beattie, T. R., Patchett, A. A., Arison, B. H., Ormond, R. E., Kuehl, F. A., Albers-Schonberg, G., and Jardetzky, O. (1969) Phosphonomycin: Structure and synthesis, Science 166, 123-124.

4. Stapley, E. O., Hendlin, D., Mata, J. M., Jackson, M., Wallick, H., Hernandez, S., Mochales, S., Currie, S. A., and Miller, R. M. (1969) Phosphonomycin. I. Discovery and in vitro biological characterization, Antimicrob. Agents Chemother. 9, 284-290.

5. Kahan, F. M., Kahan, J. S., Cassidy, P. J., and Kroop, H. (1974) The mechanism of action of fosfomycin (phosphonomycin), Ann. N.Y. Acad. Sci. 235, 364-385.

6. Marquardt, J. L., Brown, E. D., Lane, W. S., Haley, T. M., Ichskawa, Y., Wong, C.-H., and Walsh, C. T. (1994) Kinetics, stoichiometry, and identification of the reactive thiolate in the inactivation of UDP-GlcNAc enolpyruvoyl transferase by the antibiotic fosfomycin, Biochemistry 33, 10646-10651.

7. Skarzynski, T., Mistry, A., Wonacott, A., Hutchinson, S. E., Kelly, V. A., and Duncan, K. (1996) Structure of UDP-N-acetylglucosamine enolpyruvyl transferase, an enzyme essential for the synthesis of bacterial peptidoglycan, complexed with substrate UDP-N-acetylglucosamine and the drug fosfomycin, Structure 4, $1465-1474$.

8. Kadner, R. J., and Winkler, H. H. (1975) Energy coupling for methionine transport in Escherichia coli, J. Bacteriol. 123, 985991.

9. Tsuruoka, T., and Yamada, Y. (1975) Charactertization of spontaneous fosfomycin (phosphonomycin)-resistant cells of $E s$ cherichia coli B in vitro, J. Antibiot. 28, 906-911.

10. Venkateswaran, P. S., and Wu, H. C. (1972) Isolation and characterization of a phosphonomycin-resistant mutant of Escherichia coli K-12, J. Bacteriol. 110, 935-944.

11. Garcia-Lobo, J. M., and Ortiz, J. M. (1982) Tn2921, a transposon encoding fosfomycin resistance, J. Bacteriol. 151, 477-479.

12. Arca, P., Rico, M., Brana, A. F., Villar, C. J., Hardisson, C., and Suarez, J. E. (1988) Formation of an adduct between fosfomycin and glutathione: A new mechanism of antibiotic resistance in bacteria, Antimicrob. Agents Chemother. 32, 1552-1556.
13. Arca, P., Hardisson, C., and Suarez, J. E. (1990) Purification of a glutathione S-transferase that mediates fosfomycin resistance in bacteria, Antimicrob. Agents Chemother. 34, 844-848.

14. Bernat, B. A., Laughlin, L. T., and Armstrong, R. N. (1997) Fosfomycin resistance protein (FosA) is a manganese metalloglutathione transferase related to glyoxalase I and the extradiol dioxygenases, Biochemistry 36, 3050-3055.

15. Bernat, B. A., Laughlin, L. T., and Armstrong, R. N. (1999) Elucidation of a Monovalent Cation Dependence and Characterization of the Divalent Cation Binding Site of the Fosfomycin Resistance Protein, FosA, Biochemistry 38, 7462-7469.

16. Cao, M., Bernat, B. A., Wang, Z., Armstrong, R. N., and Helmann, J. D. (2001) FosB, a cysteine-dependent fosfomycin resistance protein under the control of $\sigma \mathrm{W}$, an extracytoplasmic function $\sigma$ factor in Bacillus subtilis, J. Bacteriol. 183, 2380-2383.

17. Fillgrove, K. L., Pakhomova, S., Newcomer, M. E., and Armstrong, R. N. (2003) Mechanistic diversity of fosfomycin resistance in pathogenic microorganisms, J. Am. Chem. Soc. 125, 1573015731 .

18. Rife, C. L., Pharris, R. E., Newcomer, M. E., and Armstrong, R. N. (2002) Crystal Structure of a Genomically Encoded Fosfomycin Resistance Protein (FosA) at $1.19 \AA$ A-Resolution by MAD Phasing off the L-III Edge of $\mathrm{Tl}^{+}, \mathrm{J}$. Am. Chem. Soc. 124, 11001-11003.

19. Islam, T. M., Yoshino, K., and Sasane, A. (2003) ${ }^{11}$ B NMR study of p-carboxybenzeneboronic acid ions for complex formation with some monosaccharides, Anal. Sci. 19, 455-460.

20. Rigsby, R. E., Fillgrove, K. L., Beihoffer, L., and Armstrong, R. N. (2005) Fosfomycin Resistance Proteins: A Nexus of Glutathione Transferases and Epoxide Hydrolases in a Metalloenzyme Superfamily, Methods Enzymol. 401, 367-379.

21. Otwinowski, Z., and Minor, W. (1997) Processing of X-ray diffraction data collected in oscillation mode, Methods Enzymol. 276, 307-326.

22. Collaborative Computatonal Project, Number 4 (1994) The CCP4 suite: Program for protein crystallography, Acta Crystallogr. D50, 760-763.

23. Adams, D. P., Pannu, N. S., Read, R. J., and Brunger, A. T. (1997) Cross-validated maximum likelihood enhances crystallographic simulated annealing refinement, Proc. Natl. Acad. Sci. U.S.A. 94, 5018-5023.

24. Jones, T. A., Zou, J. Y., Cowan, S. W., and Kjeldgaard, M. (1991) Improved methods for building protein models in electron density maps and the location of errors in these models, Acta Crystallogr. A47, 110-119.

25. Glaser, P., Frangeul, L., Buchrieser, C., Rusniok, C., Amend, A., Baquero, F., Berche, P., Bloecker, H., Brandt, P., Chakraborty, T., Charbit, A., Chetouani, F., Couve, E., de Daruvar, A., Dehoux, P., Domann, E., Dominguez-Bernal, G., Duchaud, E., Durant, L., Dussurget, O., Entian, K. D., Fsihi, H., Garcia-del Portillo, F., Garrido, P., Gautier, L., Goebel, W., Gomez-Lopez, N., Hain, T., Hauf, J., Jackson, D., Jones, L. M., Kaerst, U., Kreft, J., Kuhn, M., Kunst, F., Kurapkat, G., Madueno, E., Maitournam, A., Vicente, J. M., Ng, E., Nedjari, H., Nordsiek, G., Novella, S., de Pablos, B., Perez-Diaz, J. C., Purcell, R., Remmel, B., Rose, M., Schlueter, T., Simoes, N., Tierrez, A., Vazquez-Boland, J. A., Voss, H., Wehland, J., and Cossart, P. (2001) Comparative genomics of Listeria species, Science 294, 849-852.

26. Pakhomova, S., Rife, C. L., Armstrong, R. N., and Newcomer, M. E. (2004) Structure of fosfomycin resistance protein FosA from transposon Tn2921, Protein Sci. 13, 1260-1265.

27. Armstrong, R. N. (2000) Mechanistic Diversity in a Metalloenzyme Superfamily, Biochemistry 39, 13625-13632.

28. Bergdoll, M., Eltis, L. D., Cameron, A. D., Dumas, P., and Bolin, J. T. (1998) All in the family: Structural and evolutionary relationships among three modular proteins with diverse functions and variable assembly, Protein Sci. 7, 1661-1670.

29. DeLano, W. L. (2002) The PyMOL Molecular Graphics, DeLano Scientific, San Carlos, CA.

30. Lacourciere, G. M., and Armstrong, R. N. (1993) The catalytic mechanism of microsomal epoxide hydrolase involves an ester intermediate, J. Am. Chem. Soc. 115, 10466-10467.

31. Armstrong, R. N. (1999) Nucleophilic Epoxide Openings, in Comprehensive Natural Products Chemistry (Poulter, C. D., Ed.) Vol. 5, pp 51-70, Elsevier Science, Oxford, U.K.

32. Bernat, B. A., Laughlin, L. T., and Armstrong, R. N. (1998) Regiochemical and Stereochemical Course of the Reaction 
Catalyzed by the Fosfomycin Resistance Protein, FosA, J. Org. Chem. 63, 3778-3780.

33. Pettersen, E. F., Goddard, T. D., Huang, C. C., Couch, G. S., Greenblatt, D. M., Meng, E. C., and Ferrin, T. E. (2004) UCSF chimera: A visualization system for exploratory research and analysis, J. Comput. Chem. 25, 1605-1612.

BI700625P 